\title{
Use of haplotype information to test involvement of the LRP gene in Alzheimer's disease in the French population
}

\author{
Patrice Verpillat ${ }^{1,2}$, Sandrine Bouley ${ }^{2}$, Dominique Campion ${ }^{3}$, Didier Hannequin ${ }^{3}$, \\ Bruno Duboiss, Serge Belliard ${ }^{5}$, Michèle Puel ${ }^{6}$, Catherine Thomas-Antérion ${ }^{7}$, Yves Agid ${ }^{2,4}$, \\ Alexis Brice $\mathrm{e}^{2,4,8}$ and Françoise Clerget-Darpoux ${ }^{1}$
}

${ }^{1}$ INSERM U535, Le Kremlin Bicêtre, France; ${ }^{2}$ INSERM U289, Paris, France; ${ }^{3}$ INSERM EPI 9906, Rouen, France; ${ }^{4}$ Fédération de Neurologie, Hôpital de la Salpêtrière, Paris, France; ${ }^{5}$ Service de Neurologie, Hôpital de Pontchaillou, Rennes, France; ${ }^{6}$ Service de Neurologie, Hôpital Purpan, Toulouse, France; ${ }^{7}$ Service de Neurologie, Centre Hospitalier Universitaire, Saint-Etienne, France; ${ }^{8}$ Dèpartement de Génètique, Cytogènètique et Embryologie, Hôpital de la Salpêtrière, Paris, France

The low density lipoprotein receptor-related protein gene (LRP) is a good candidate gene for Alzheimer's Disease (AD). Its protein is involved in the physiopathology of $A D$ and has been found in senile plaques; on the other hand, LRP is located in 12q, a region in which genetic linkage to AD was reported. Two common polymorphisms, a tetranucleotide repeat in the $5^{\prime}$ untranslated region and a single nucleotide polymorphism at position 766 in exon 3, were found to be associated with AD, but contradictory results were obtained in subsequent association studies. In the absence of clear hypotheses concerning the association of these polymorphisms with $A D$ and their functional role, our objective was to test the association between $A D$ and the two LRP polymorphisms in a large French case-control sample (274 Caucasian AD patients and 290 matched controls) using haplotype analysis. First, the separate study of each polymorphism showed no significant difference in genotype and allele frequencies between AD cases and controls. Second, strong linkage disequilibrium was found between alleles of the two polymorphisms in controls and in cases and the linkage disequilibrium between the $91 \mathrm{bp}$ and $\mathrm{C}$ alleles were opposite in cases and in controls. Third, we found that the frequency of the 91-C haplotype was higher in cases than in controls, but the type I error was 0.061 , slightly higher than the conventional one of $5 \%$. The haplotype frequencies did not vary significantly as a function of age and APOE $\varepsilon 4$ status. One interest in this study is the use of the haplotype analysis, which can be used to combine information from several polymorphisms, taking into account their dependence. European Journal of Human Genetics (2001) 9, 464-468.

Keywords: LRP; Alzheimer's disease; haplotype analysis; linkage disequilibrium; French population

*Correspondence: Dr P Verpillat, INSERM U535, 80 rue du Général Leclerc, 94276 Le Kremlin Bicêtre cedex, France; Tel: +33 1455953 30; Fax: +33 1455953 33; E-mail: patrice.verpillat@bch.ap-hop-paris.fr Received 2 January 2001; revised 20 February 2001; accepted 27 February 2001

\section{Introduction}

The major known genetic risk factor for non-autosomal dominant Alzheimer's Disease (AD) is undeniably the apolipoprotein E gene (APOE for the gene, apoE for the protein). However, Martinez et al. ${ }^{1}$ have demonstrated that familial aggregation was not fully explained by this genetic risk factor. Thus, other genes may account for the remaining risk of developing $\mathrm{AD}$. Recently, five linkage 
studies $^{2-6}$ reported evidence of an AD susceptibility locus on chromosome 12 where the low density lipoprotein receptor-related protein gene (LRP) is located. LRP is therefore a good candidate gene. Indeed, several observations suggest a potential role for this gene and its protein in the pathogenesis of AD. LRP is a multifunctional ligand receptor expressed in neurons. It is the main apoE receptor in the brain. ${ }^{7}$ It mediates neurite outgrowth in an apoEisoform-dependent manner. ${ }^{8}$ It is responsible for the endocytosis of secreted amyloid precursor protein (APP), ${ }^{9}$ also implicated in the pathogenesis of $\mathrm{AD}$, and is detected in senile plaques, dystrophic neurites and reactive astrocytes in $\mathrm{AD}$ brain. ${ }^{10}$

A genetic association between two different LRP polymorphisms and $\mathrm{AD}$ has been reported. The first polymorphism was a (TTTC)n repeat in the $5^{\prime}$ untranslated region (UTR) of the gene. Four different alleles have been described to date, corresponding to 83, 87, 91 and 95 basepair (bp) PCR products. ${ }^{11}$ The 87 and $91 \mathrm{bp}$ alleles are the most frequent. Lendon et al. ${ }^{12}$ reported a significant increase of the $87 \mathrm{bp}$ allele in $\mathrm{AD}$ cases in an American population $(P=0.008)$. In a French population, Lambert et al. ${ }^{13}$ reported a significant increase in the $91 \mathrm{bp}$ allele in AD cases $(P=0.0032)$, but this association was not confirmed in four other studies. ${ }^{14-17}$ The second polymorphism was a silent point substitution in exon 3 , in which base 766 is changed from cytosine (C) to thymine (T) but does not modify the amino acid sequence. Kang et al. ${ }^{18}$ found that the CC genotype was associated with an increased risk for $\mathrm{AD}(P=0.0024)$, a finding that was subsequently confirmed by four of six independent studies, including one in France. ${ }^{16,19-23}$ Its effect was age-dependent and/or APOE status-dependent in some but not all studies.

Differences in genetic background between American and French populations might explain the contradictory results obtained concerning the first polymorphism. Linkage disequilibrium (LD) between alleles at this locus and a biologically relevant variant elsewhere in the gene may differ among populations. The second polymorphism is a neutral locus. The observed association with $\mathrm{AD}$ might only reflect the LD between this polymorphism and the functional variant. It is not therefore on the basis of these polymorphisms that LRP can be considered a genetic risk factor for AD. Another functional variant may be in LD with each of these polymorphisms, which may then be themselves associated with AD by a 'hitchhiking' effect. ${ }^{24-26}$ Thomson $^{24}$ has shown that a 'hitchhiking' selection event can create LD between neutral loci, which are also passengers in this putative 'hitchhiking' event.

The present study is based on a three-locus 'hitchhiking' model, where one locus is selected, whereas the other two are selectively neutral. We used haplotype information to test the association between AD and the two LRP polymorphisms in a large French case-control sample, taking into account the possible non-independence of the two polymorphisms.

\section{Methods \\ Subjects}

Our sample was composed of 274 unrelated AD cases $(44.2 \%$ male). All patients were ascertained over a 5-year period through consecutive admissions to several university hospitals in France. The diagnosis of probable AD was established according to the criteria of the National Institute of Neurological and Communicative Disorders and Stroke Alzheimer Disease and Relative Disorders Association (NINCDS-ADRDA). ${ }^{27}$ Age at onset was assessed by interviewing next of kin and was defined as the age at which the patient or his family first noticed the symptoms required for the diagnosis (mean age at onset $=65.5 \pm 9.8$ years; range $=41-$ 90). Patients from families characterised by autosomal dominant inheritance were excluded.

$\mathrm{AD}$ patients were compared to 290 age- and sex-matched controls $(43.1 \%$ male; mean age at examination $=67.4 \pm 10.0$ years; range $=43-93$ ). Control subjects were either patients' spouses, healthy blood donors or individuals living in retirement homes. All controls were screened for cognitive function. None showed cognitive deficit.

All subjects were Caucasian and lived in France. Informed consent was obtained for each subject either directly or from a legal tutor.

\section{Genetic analysis. LRP repeat (TTTC)n}

To study the tetranucleotide repeat polymorphism, we have used primers described by Zuliani and Hobbs. ${ }^{28}$ PCR amplification was performed in $25 \mu \mathrm{l}$ of PCR buffer containing $2 \mathrm{mM} \mathrm{MgCl}_{2}, 7.5 \mathrm{mM}$ dNTP, $1 \mathrm{U}$ of taq DNA polymerase, 15 pmol of each primer and 200 ng of DNA, with 35 cycles of $94^{\circ} \mathrm{C}$ for $1 \mathrm{~min}$ and $60^{\circ} \mathrm{C}$ for $3 \mathrm{~min}$ and a final extension of $7 \mathrm{~min}$ at $72^{\circ} \mathrm{C}$. Electrophoresis and genotype analyses were performed as described above.

\section{Exon $3 \mathrm{C} / \mathrm{T}$ polymorphism}

PCR primers were designed to amplify $167 \mathrm{bp}$ around the $\mathrm{C} / \mathrm{T}$ polymorphism in LRP exon 3 as described by Hollenbach et al. ${ }^{19}$ The digested products were pooled with the Genscan 500 HD size standard and loaded on a $4.5 \%$ denaturing acrylamide gel for electrophoresis with the ABI PRISM 377 DNA sequencer (Perkin Elmer). Each genotype was determined by analysing data with Genscan 3.0 and Genotyper 1.1.1 software.

\section{Statistical analysis}

Statistical analyses were performed with the SAS software release 8.0 (SAS Institute Inc, Nashville, TN, USA). For initial comparisons, two-sided $\chi^{2}$ test and Fisher exact test when necessary were used to determine potential differences in the distribution of LRP genotypes and alleles between groups. For the comparison of each polymorphism separately, the Bonferroni correction was applied for two-group comparisons and the alpha level for each test was set at 0.0253 to bring the alpha level overall back to 0.05 . Using this corrected 
alpha level, we next estimated the power of the study to detect a difference assuming an OR value of 2 , which correspond to an intermediate value between the OR found by Lambert et al. ${ }^{13}(1.6,95 \%$ CI [1.1-2.2]) and the one found by Kang et al. ${ }^{18}$ (2.41, [1.4-4.2]). Power computations were made with nQuery Advisor ${ }^{\circledR}$ Release 4.0.

The $\mathrm{EH}$ program ${ }^{29,30}$ was used to test the existence of linkage disequilibrium between alleles at both loci of the two polymorphisms and to estimate the frequencies of the LRP haplotypes. Haplotype frequencies were estimated in controls and in cases with allelic association $\left(\mathrm{H}_{1}\right)$ and without $\left(\mathrm{H}_{0}\right)$ by maximising the likelihood, testing first HardyWeinberg equilibrium (HWE) in both samples. Departure from HWE may be a substantial source of error in $\mathrm{EH}$ haplotype frequency estimations based on the expectationmaximization algorithm, simply because this algorithm uses HWE in its expectation step. ${ }^{31}$ The EH program also provides $\log$ likelihood, $\chi^{2}$ and the number of degrees of freedom under hypotheses $\mathrm{H}_{0}$ and $\mathrm{H}_{1}$. To compare the homogeneity of haplotype frequencies in cases and controls, a likelihood homogeneity test was performed as follows. Three samples, $\mathrm{s}_{\mathrm{co}}$ for control, $\mathrm{s}_{\mathrm{ca}}$ for case and $\mathrm{s}_{\mathrm{p}}$ for the pooled sample (cases+controls) were considered. Haplotype frequencies $\left(\mathrm{f}_{\mathrm{co}}\right.$, $\left.\mathrm{f}_{\mathrm{ca}}, \mathrm{f}_{\mathrm{p}}\right)$ and the corresponding likelihood $\left(\mathrm{L}_{\mathrm{co}}, \mathrm{L}_{\mathrm{ca}}, \mathrm{L}_{\mathrm{p}}\right)$ were estimated by the $\mathrm{EH}$ program for controls, cases and pooled sample, respectively. To test the homogeneity of $\mathrm{f}_{\mathrm{co}}$ and $\mathrm{f}_{\mathrm{ca}}$, the quantity $2\left(\ln L_{c o}+\ln L_{c a}-\ln L_{p}\right)$ followed a $\chi^{2}$ test with one degree of freedom. The same principle was applied to test the homogeneity of haplotype frequencies in cases and controls as a function of age ( $<65$ or $\geqslant 65$ years) and APOE $\varepsilon 4$ status (carriers of at least one $\varepsilon 4$ allele or non-carriers).

\section{Results}

We first studied the association of each LRP polymorphism with AD. The genotype and allele distributions of these polymorphisms are presented in Table 1 . No deviation from the Hardy-Weinberg equilibrium was observed for any of the polymorphisms in controls and AD cases. There was no $95 \mathrm{bp}$ allele in our sample. No significant difference in genotype distributions between $\mathrm{AD}$ cases and controls was observed neither for the tetranucleotide polymorphism $(P=0.073)$, nor for the polymorphism in exon $3(P=0.365)$. The frequency of the 91bp allele was increased in $\mathrm{AD}$ cases compared with controls but the difference was not statistically significant $(P=0.231)$. For the exon 3 polymorphism, allele frequencies were identical between AD cases and controls $(P=0.982)$. Assuming a 0.0253 two-sided significance level, the size of our sample was sufficient to detect a difference with a power of $80 \%$ assuming an OR of 2 for developing $\mathrm{AD}$ when bearing at least one $91 \mathrm{bp}$ allele ${ }^{13}$ and of $84 \%$ assuming an OR of 2 when bearing the CC genotype. ${ }^{18}$

Since the two polymorphisms in the LRP gene are physically close to each other, we next tested for linkage disequilibrium between them in controls and cases. Their alleles were in strong linkage disequilibrium (Table 2). Very interestingly, the two at-risk alleles in the French population, the $91 \mathrm{bp}$ and $\mathrm{C}$ alleles, were negatively associated in controls and positively associated in cases. The opposite was found for the $91 \mathrm{bp}$ and $\mathrm{T}$ alleles. In addition, the $83 \mathrm{bp}$ allele was in complete linkage disequilibrium with the $\mathrm{T}$ allele. There was no 83-C haplotype in our sample.

The haplotype frequencies, in cases and controls, estimated by the EH program under the hypothesis of linkage disequilibrium between the alleles of the two polymorphisms are presented in Table 3. The two most frequent haplotypes were 91-C and 87-C. Because the frequencies of the three other haplotypes were lower than $10 \%$ in cases and in controls, we decided to pool them. Three haplotypes were therefore compared: two with the at-risk allele $\mathrm{C}$ combined with either the $91 \mathrm{bp}$ allele (at-risk in the French population) or the $87 \mathrm{bp}$ allele (at-risk in the American population), and the third consisting of all the other haplotypes pooled. The frequency of the 91-C haplotype was higher in cases than in controls, although the result did not quite reach statistical significance when corrected for the number of haplotypes tested $(P=0.061)$. We have calculated that in our sample, the power to detect an effect of equivalent size $(\mathrm{OR}=2)$ to that used to previous power computations was equal to $99 \%$, assuming a 0.05 two-sided significance level when considering an OR for developing $\mathrm{AD}$ when bearing the 91-C haplotype. This haplotype was interesting because it contained the two alleles which were found to be at-risk in two other independent French samples. The homogeneity of the frequency of this haplotype was then studied as a function of age and APOE status. Four categories were considered according to age and APOE status (Table 4). Since all these frequencies were estimated by maximisation of likelihood, we estimated their likelihood and then compared them by a likelihood homogeneity test for each category of cases and controls. No differences were significant at $5 \%$.

\section{Discussion}

The study of each LRP polymorphism separately showed no significant results after Bonferroni correction. By the haplotypic approach, we found that the 91-C haplotype was more frequent in $\mathrm{AD}$ cases than in controls, although statistical significance was borderline at the 5\% level when corrected for the number of haplotypes tested. The correction for multiple testing is a major problem in genetic studies in which many polymorphisms are studied without correction. This lack of correction for multiple tests can lead to falsepositive results. However, correcting for multiple tests decreases the power to detect true risk factors. One solution is to test an a priori hypothesis in a replication study. In the present study, since the $91 \mathrm{bp}$ and $\mathrm{C}$ alleles were found to be at-risk in two other French studies with independent samples, ${ }^{13,21}$ it would have been possible to test only the increase in the 91-C haplotype versus the others. The 
Table 1 Genotype (a) and allele (b) frequencies for each LRP polymorphism

\begin{tabular}{llc}
\hline $\begin{array}{l}\text { (a) } \\
\text { Genotypes }\end{array}$ & $\begin{array}{l}\text { AD cases } \\
(\mathrm{n}=274)\end{array}$ & $\begin{array}{l}\text { Controls } \\
(\mathrm{n}=290)\end{array}$ \\
\hline $\begin{array}{l}\text { (TTTC) } \mathrm{n} \text { repeat } \\
83 / 83\end{array}$ & $0(0)$ & $0.3(1)$ \\
$83 / 87$ & $1.1(3)$ & $1.7(5)$ \\
$83 / 91$ & $2.2(6)$ & $0.3(1)$ \\
$87 / 87$ & $14.2(39)$ & $21.0(61)$ \\
$87 / 91$ & $46.4(127)$ & $42.1(122)$ \\
$91 / 91$ & $36.1(99)$ & $34.5(100)$ \\
Exon 3 & $72.3(198)$ & $73.8(214)$ \\
CC & $25.9(71)$ & $22.8(66)$ \\
CT & $1.8(5)$ & $3.4(10)$ \\
TT & & \\
(b) & $A D$ cases & Controls \\
Alleles & $(\mathrm{n}=548)$ & $(\mathrm{n}=580)$ \\
\hline (TTTC) $\mathrm{n}$ repeat & & \\
83 & $1.6(9)$ & $1.4(8)$ \\
87 & $38.0(208)$ & $42.9(249)$ \\
91 & $60.4(331)$ & $55.7(323)$ \\
Exon 3 & & \\
C & $85.2(467)$ & $85.2(494)$ \\
T & $14.8(81)$ & $14.8(86)$ \\
\hline
\end{tabular}

Table 2 Linkage disequilibrium between the alleles of the two LRP polymorphisms in controls (a) and in cases (b). In brackets: maximum possible value of the linkage disequilibrium coefficient, at the given allele frequencies ( $D^{\prime}$ percentage).

\begin{tabular}{lcr}
\hline $\begin{array}{l}\text { (a) } \\
\text { Polymorphism in the 5' UTR }\end{array}$ & \multicolumn{2}{c}{ Polymorphism in exon 3} \\
\hline $83 \mathrm{bp}$ & $T(\%)$ \\
$87 \mathrm{bp}$ & $-0.012(100)$ & $0.012(100)$ \\
$91 \mathrm{bp}$ & $0.034(53)$ & $-0.034(53)$ \\
& $-0.022(34)$ & $0.022(34)$ \\
(b) & & \\
\hline $83 \mathrm{bp}$ & $-0.014(100)$ & $0.014(100)$ \\
$87 \mathrm{bp}$ & $0.012(21)$ & $-0.012(21)$ \\
$91 \mathrm{bp}$ & $0.002(2)$ & $-0.002(2)$ \\
\hline
\end{tabular}

Table 3 Frequencies of LRP haplotypes in AD cases and controls

\begin{tabular}{lll}
\hline & $\begin{array}{l}\text { AD cases } \\
(\mathrm{n}=548)\end{array}$ & $\begin{array}{l}\text { Controls } \\
(\mathrm{n}=580)\end{array}$ \\
\hline Haplotype & & \\
$91-\mathrm{C}$ & $51.6(283)$ & $45.2(262)$ \\
$87-\mathrm{C}$ & $33.6(184)$ & $40.0(232)$ \\
Others* & $14.8(81)$ & $14.8(86)$ \\
\hline
\end{tabular}

*91-T, 87-T, 83-T; $P=0.061$.
Table 4 Frequencies of the 91-C haplotype according to age and APOE status

\begin{tabular}{lllll}
\hline & $<65$ & $<65$ & $\geqslant 65$ & $\geqslant 65$ \\
& APOE4 - & APOE4+ & APOE4 - & \begin{tabular}{l} 
APOE4+ \\
\hline Cases
\end{tabular} \\
Controls & $57.2(83)$ & $52.2(67)$ & $42.3(46)$ & $54.8(91)$ \\
\hline
\end{tabular}

resulting $P$-value would have been 0.03 and the OR 1.30 (95\% CI $[1.03-1.64])$.

It is necessary to apply a correction when two independent tests are performed successively. However, when the two polymorphisms are not independent, as for the two LRP polymorphisms studied, this correction is too conservative. In the extreme case where there is complete linkage disequilibrium between two polymorphisms, testing association with one of the alleles is exactly the same as testing association with the other. This is one strength of the haplotypic approach used in our study. Indeed, haplotype analysis combines information concerning several polymorphisms by taking into account their dependence, rather than studying each polymorphism separately.

The existence of LD between the studied polymorphisms could result in the absence of some haplotypes, as it was the case for the 83-C haplotype in our study. Under the hypothesis that a functional allele is in LD with the polymorphisms studied (three-locus 'hitchhiking' model), LD of opposite signs may be observed in cases and controls, as for the $91 \mathrm{bp}$ and C/T alleles in our study. In this case, the power of a haplotype test to detect the association may be greater than testing the polymorphisms separately (paper in preparation).

As an increasing number of polymorphisms are studied in candidate genes, the haplotypic approach that takes into account the possible non-independence between all these polymorphisms, permits better use of all available information.

\section{Acknowledgements}

We thank all members of the French Alzheimer's disease genetic study group for their contributions; Jacqueline Bou, Christiane Penet and Yolaine Pothin for their technical assistance. We are most grateful to all participants in the study.

\section{References}

1 Martinez M, Campion D, Brice A, et al: Apolipoprotein E $\varepsilon 4$ allele and familial aggregation of Alzheimer disease. Arch Neurol 1998; 55: $810-816$.

2 Pericak-Vance MA, Bass MP, Yamaoka LH, et al: Complete genomic screen in late-onset familial Alzheimer disease: evidence for a new locus on chromosome 12. JAMA 1997; 278: $1237-1241$. 
3 Zubenko GS, Hughes HB, Stiffler JS, Hurtt MR, Kaplan BB: A genome survey for novel Alzheimer disease risk loci : results at 10-cM resolution. Genomics 1998; 50: 121-128.

4 Rogaeva E, Premkumar S, Song Y, et al: Evidence for an Alzheimer disease susceptibility locus on chromosome 12 and for further locus heterogeneity. JAMA 1998; 280: 614-618.

5 Kehoe P, Wavrant-de Vriéze F., Crook R, et al: A full genome scan for late onset Alzheimer's disease. Hum Mol Genet 1999; 8: 237 245.

6 Scott WK, Grubber JM, Abou-Donia SM, et al: Further evidence linking late-onset Alzheimer disease with chromosome 12 . JAMA 1999; 281: 513-514. Letter.

7 Fagan AM, Bu G, Sun Y, Daugherty A, Holtzman DM: Apolipoprotein E-containing high density lipoprotein promotes neurite outgrowth and is a ligand for the low density lipoprotein receptor-related protein. J Biol Chem 1996; 271: $30121-30125$.

8 Holtzman DM, Pitas RE, Kilbridge J, et al: Low density lipoprotein receptor related protein mediates apolipoprotein E-dependent neurite outgrowth in a central nervous systemderived neuronal cell line. Proc Natl Acad Sci USA 1995; 92: $9480-9484$

9 Kounnas MZ, Moir RD, Rebeck GW, et al: LDL receptor-related protein, a multifunctional apoE receptor, binds secreted $\beta$ amyloid precursor protein and mediates its degradation. Cell 1995; 82: $331-340$.

10 Rebeck GW, Harr SD, Strickland DK, Hyman BT: Multiple, diverse senile plaque associated proteins are ligands of an apolipoprotein receptor, the alpha 2 macroglobulin/low density lipoprotein-related protein. Ann Neurol 1995; 37: 211 - 217.

11 Harris M, Sanghera DK, Kamboh MI: Two new alleles in the tetranucleotide repeat polymorphism in the LDL-receptorrelated protein (LRP) gene. Clin Genet 1996; 50: 54-55.

12 Lendon CL, Talbot CJ, Craddock NJ, et al: Genetic association studies between dementia of the Alzheimer's type and three receptors for apolipoprotein $\mathrm{E}$ in a caucasian population. Neurosci lett 1997; 222: 187-190.

13 Lambert J-C, Chartier-Harlin M-C, Cottel D, et al: Is the LDL receptor-related protein involved in Alzheimer's disease? Neurogenetics 1999; 2: 109-113.

14 Fallin D, Kundtz A, Town T, et al: No association between the low density lipoprotein receptor-related protein (LRP) gene and late-onset Alzheimer's disease in a community-based sample. Neurosci Lett 1997; 233: 145 - 147.

15 Clatworthy AE, Gomez-Isla T, Rebeck GW, Wallace RB, Hyman BT: Lack of association of a polymorphism in the low-density lipoprotein receptor-related protein gene with Alzheimer disease. Arch Neurol 1997; 54: 1289-1292.

16 Kamboh MI, Ferrell RE, DeKosky ST: Genetic association studies between Alzheimer's disease and two polymorphisms in the low density lipoprotein receptor-related protein gene. Neurosci Lett 1998; 244: $65-68$
17 Scott WK, Yamaoka LH, Bass MP, et al: No genetic association between the LRP receptor and sporadic or late-onset familial Alzheimer disease. Neurogenetics 1998; 1: 179-183.

18 Kang DE, Saitoh T, Chen X, et al: Genetic association of the lowdensity lipoprotein receptor-related protein gene (LRP), an apolipoprotein E receptor, with late-onset Alzheimer's disease. Neurology 1997; 49: 56-61.

19 Hollenbach E, Ackermann S, Hyman BT, Rebeck GW: Confirmation of an association between a polymorphism in exon 3 of the low density lipoprotein receptor-related protein gene and Alzheimer's disease. Neurology 1998; 50: 1905 - 1907.

20 Baum L, Chen L, Ng H-K, et al: Low density lipoprotein receptor related protein gene exon 3 polymorphism association with Alzheimer's disease in Chinese. Neurosci Lett 1998; 247: 33 - 36

21 Lambert J-C, Wavrant-de Vriéze F, Amouyel P, Chartier-Harlin M-C: Association at LRP gene locus with sporadic late-onset Alzheimer's disease. Lancet 1998; 351: 1787-1888.

22 Woodward R, Singleton AB, Gibson AM, Edwardson JA, Morris CM: LRP gene and late-onset Alzheimer's disease. Lancet 1998; 352: $239-240$.

23 Beffert U, Arguin C, Poirier J: The polymorphism in exon 3 of the low density lipoprotein receptor-related protein gene is weakly associated with Alzheimer's disease. Neurosci Lett 1999; 259: $29-32$.

24 Thomson G: The effect of a selected locus on linked neutral loci Genetics 1977; 85: $753-788$

25 Robinson WP, Cambon-Thomsem A, Borot N, Klitz W, Thomson G: Selection, hitchhiking and disequilibrium analysis at three linked loci with application to HLA data. Genetics 1991; 129: $931-948$

26 Thomson G, Baur MP: Third order linkage disequilibrium. Tissue Antigens 1984; 24: 250-255.

27 McKahn G, Drachman D, Folstein M, Karzman R, Price D, Stadlan E: Clinical diagnosis of Alzheimer's disease : report of the NINCDS-ADRA work group. Neurology 1984; 34: 939-944.

28 Zuliani G, Hobbs HH: Tetranucleotide length polymorphism 5 of the alpha 2-macroglobulin receptor (A2MR)/LDL receptorrelated protein (LRP) gene. Hum Mol Genet 1994; 3: 215.

29 Xie X, Ott J: Testing linkage disequilibrium between a disease gene and marker loci. Am J Hum Genet 1993; 53: 1107.

30 Terwilliger J, Ott J: Handbook of Human Genetic Linkage. Johns Hopkins University Press, Baltimore (1994).

31 Fallin D, Schorck NJ: Accuracy of haplotype frequency estimation for biallelic loci, via the expectation-maximization algorithm for unphased diploid genotype data. Am J Hum Genet 2000; 67: 947 - 959 . 